\title{
Trophic relationships between predators, whiteflies and their parasitoids in tomato greenhouses: a molecular approach
}

\author{
R. Moreno-Ripoll ${ }^{1}$, R. Gabarra ${ }^{1}$, W.O.C. Symondson ${ }^{2}$, \\ R.A. King $^{2+}$ and N. Agustí ${ }^{1 *}$ \\ ${ }^{1}$ IRTA, Entomology, Ctra. de Cabrils, Km. 2, E-08348 Cabrils, Barcelona, \\ Spain: ${ }^{2}$ Cardiff School of Biosciences, Biomedical Sciences Building, \\ Cardiff University, Museum Avenue, Cardiff, CF10 3AX, UK
}

\begin{abstract}
The whiteflies Bemisia tabaci Gennadius and Trialeurodes vaporariorum (Westwood) (Hemiptera: Aleyrodidae) are two of the main pests in tomato crops. Their biological control in Mediterranean IPM systems is based on the predators Macrolophus pygmaeus (Rambur) and Nesidiocoris tenuis Reuter (Hemiptera: Miridae), as well as on the parasitoids Eretmocerus mundus (Mercet) and Encarsia pergandiella Howard (Hymenoptera: Aphelinidae). These natural enemies may interact with each other and their joint use could interfere with the biological control of those whitefly pests. Analysis of predator-prey interactions under field conditions is therefore essential in order to optimize whitefly control. Species-specific polymerase chain reaction (PCR)primers were designed to detect DNA fragments of these whiteflies and parasitoids within both predator species in tomato greenhouses. We demonstrated that both predators feed on both whitefly species, as well as on both parasitoids under greenhouse conditions. Prey molecular detection was possible where prey abundance was very low or even where predation was not observed under a microscope. Whitefly DNA detection was positively correlated with adult whitefly abundance in the crop. However, a significant relationship was not observed between parasitoid DNA detection and the abundance of parasitoid pupae, even though the predation rate on parasitoids was high. This unidirectional intraguild predation (predators on parasitoids) could potentially reduce their combined impact on their joint prey/ host. Prey molecular detection provided improved detection of prey consumption in greenhouse crops, as well as the possibility to identify which prey species were consumed by each predator species present in the greenhouse, offering a blueprint with wider applicability to other food webs.
\end{abstract}

Keywords: gut-content analysis, species-specific molecular markers, polyphagous predators, parasitism, tomato crops, Bemisia tabaci, Trialeurodes vaporariorum, Macrolophus pygmaeus, Nesidiocoris tenuis, Eretmocerus mundus, Encarsia pergandiella

(Accepted 30 November 2011; First published online 7 February 2012)

*Author for correspondence

Fax: (34) 937533954

E-mail: nuria.agusti@irta.cat

tCurrent address: College of Life and Environmental Sciences, Geoffrey Pope Building, University of Exeter Stocker Road, Exeter, EX4 4QD UK 


\section{Introduction}

Biological control in intensive crops is usually based on the inoculation and/or conservation of predator and parasitoid species to control pests that invade the crop (Albajes \& Alomar, 1999). In Mediterranean tomato crops, the whiteflies Bemisia tabaci Gennadius and Trialeurodes vaporariorum (Westwood) (Hemiptera: Aleyrodidae) are two of the main pests. They can cause significant reductions in crop yield by either feeding directly on the plant leaves or by producing honeydew, on which sooty mold develops quickly. This mold hampers photosynthesis and respiration, and renders fruits unmarketable. Also, several viruses that severely affect protected vegetable crops worldwide are transmitted by these whitefly species. In particular, $B$. tabaci transmits the Tomato Yellow Leaf Curl Disease that causes severe crop losses (Gabarra \& Besri, 1999; Avilla et al., 2004). In order to control these whitefly species, two polyphagous predators, Macrolophus pygmaeus (Rambur) and Nesidiocoris tenuis Reuter (Hemiptera: Miridae), have been shown to reduce whitefly populations in greenhouses (Albajes et al., 2003; Calvo et al., 2009). Until recently, M. pygmaeus found on tomato has been misidentified as $M$. caliginosus Wagner (=M. melanotoma (Costa)) and is still named as M. caliginosus by commercial producers (Martinez-Cascales et al., 2006). Macrolophus pygmaeus and $N$. tenuis spontaneously colonize Mediterranean tomato crops when spray applications are reduced, and IPM programs based on conservation of these natural enemies are applied (Castañé et al., 2004).

Parasitoids are also used in biological control of whiteflies in protected crops. Abundant naturally occurring populations of Eretmocerus mundus (Mercet) and Encarsia pergandiella Howard (Hymenoptera: Aphelinidae) are also present in IPM tomato crops in northeast Spain (Gabarra et al., 1999; Arnó et al., 2005). Eretmocerus mundus, which is commercially available, specifically parasitizes B. tabaci, while E. pergandiella parasitizes both $T$. vaporariorum and $B$. tabaci. Therefore, it is common to find the two whitefly species, the two whitefly parasitoids and the two predator species, in the same tomato crop. The natural enemies may interact with each other and their joint use could either have an additive, positive synergistic or negative effect on the control of pest species. For this reason, the analysis of this food web under natural field conditions is essential if the mechanics of the interactions are to be understood. Better understanding of trophic relationships and the control capacities of the species involved, acting in concert, should allow better strategies to be devised for the optimization of whitefly control.

In field situations, prey choice by predators is not easily quantified by direct observations and is made much more difficult where cryptic species are involved. Apart from direct observation, predation on whiteflies has usually been estimated by counting the remains of whitefly pupae (Castañe et al., 2004), but this measure is the result of the accumulation of predated whitefly pupae over time. When more than one predator is present in the crop, it is impossible to determine which one has consumed the target prey. An alternative approach is to use microscopic examination of gut contents to identify prey remains in predators, but this is only possible if indigestible solid remains are present in the foregut. Many arthropod predators, including the Hemiptera, are fluid feeders, making this approach impossible. In addition, predation on parasitized whitefly nymphs is even more difficult to evaluate because of the difficulty of finding parasitoid early stages, even by dissection.

In recent years, molecular techniques have facilitated the detection of prey remains within predator gut contents, generally by identifying prey-specific protein or DNA sequences (Symondson, 2002). Currently, the most common way to analyze dietary studies of arthropods is by DNA-based gut content analysis using prey-specific molecular markers, which can provide accurate information about which predator species has fed on a particular target prey (King et al., 2008; Kuusk \& Agustí, 2008). This approach has also been successfully used to detect parasitoid DNA within hosts (Agustí et al., 2005; Traugott \& Symondson, 2008). Molecular detection of predation and parasitism (reviewed by Gariepy et al., 2007; King et al., 2008) is now a well-proven technology, with increasing numbers of studies conducted in the field (Agustí et al., 2003; Harper et al., 2005; Harwood et al., 2007; Juen \& Traugott, 2007; Zhang et al., 2007; Kuusk et al., 2008). However, among all of them, few have been focused on predation of parasitized prey under field conditions (Chacón et al., 2008; Traugott et al., 2011) and none in tomato crops.

It was, therefore, the aim of this study to test the existence and extent of trophic interactions between predators and parasitoids of whiteflies under greenhouse conditions, which could interfere with the biological control of those whitefly pests.

\section{Materials and methods}

Insects

Macrolophus pygmaeus and $N$. tenuis were reared at our facilities (IRTA, Cabrils) as described in Agustí \& Gabarra $(2009 a, b)$. This colony is renewed every year with introductions of new field-collected insects from the same area. They were fed with Ephestia kuehniella Zeller (Lepidoptera: Pyralidae) eggs on tobacco. Ephestia kuehniella eggs were provided by Biotop (Valbonne, France). Bemisia tabaci and T. vaporariorum were reared on cabbage and tomato, respectively. Eretmocerus mundus was reared on B. tabaci on cotton plants. All insects were reared under controlled conditions of $25 \pm 2^{\circ} \mathrm{C}, 70 \pm 10 \% \mathrm{RH}$ and L16:D8 photoperiod. The remaining species were obtained from crops near the study site.

\section{Primer design, DNA extraction and amplification}

Two pairs of specific primers, Bt2F/Bt3R and Tv1F/Tv1R, were designed for B. tabaci and T. vaporariorum, respectively, from the mitochondrial cytochrome oxidase I (COI) region. Several sequences from the GenBank database (www.ncbi. nlm.nih.gov) were used as reference sequences to design species-specific primers for the COI gene for $B$. tabaci (AM691052, B. tabaci; AF418672 and AF110708, T. vaporariorum; AY842502, Aphis gossypii; DQ059302, Helicoverpa armigera) and T. vaporariorum (AY521259, B. tabaci; AY521265, T. vaporariorum; AY227082, Aphis gossypii; AY437834, H. armigera). Similarly, GenBank reference sequences for the ITS-1 region were used in the development of specific primers for E. mundus, Em2F/Em1R and E. pergandiella, Ep1F/Ep1R (AY854061, B. tabaci; AY854055, T. vaporariorum; AF273635, E. mundus; AY615778, E. pergandiella). In this case, ITS-1 region was used because of the impossibility of finding enough differences in the COI region to design specifics primers. Sequence alignments were performed using CLUSTALW 
Table 1. Prey, parasitoid and predator species tested for cross-amplification using whitefly and parasitoid specific primers described in table 2.

\begin{tabular}{|c|c|c|c|}
\hline Group & Order & Family & Species tested \\
\hline \multirow[t]{12}{*}{ Prey } & Acari & Tetranychidae & Tetranychus urticae Koch \\
\hline & Diptera & Agromyzidae & Liriomyza trifolii (Burgess) \\
\hline & Homoptera & Aleyrodidae & Aleyrodes proletella (Linnaeus) \\
\hline & & & Bemisia tabaci Gennadius \\
\hline & & & Trialeurodes vaporariorum (Westwood) \\
\hline & & Aphididae & Aphis gossypii Glover \\
\hline & & & Nasonovia ribisnigri (Mosley) \\
\hline & Lepidoptera & Noctuidae & Chrysodeixis chalcites (Esper) \\
\hline & & & Helicoverpa armigera (Hübner) \\
\hline & & & Autographa gamma Linnaeus \\
\hline & & Pyralidae & Ephestia kuehniella Zeller \\
\hline & Thysanoptera & Thripidae & Frankliniella occidentalis (Pergande) \\
\hline \multirow[t]{6}{*}{ Predator } & Diptera & Cecidomyiidae & Aphidoletes aphidimyza (Rondani) \\
\hline & Hemiptera & Anthocoridae & Orius laevigatus (Fieber) \\
\hline & & & Orius majusculus (Reuter) \\
\hline & Heteroptera & Miridae & Dicyphus tamaninii Wagner \\
\hline & & & Macrolophus pygmaeus (Rambur) \\
\hline & & & Nesidiocoris tenuis Reuter \\
\hline \multirow[t]{8}{*}{ Parasitoid } & Hymenoptera & Aphelinidae & Encarsia formosa Gahan \\
\hline & & & Encarsia pergandiella Howard \\
\hline & & & Eretmocerus eremicus Rose and Zolnerowich \\
\hline & & & Eretmocerus mundus (Mercet) \\
\hline & & Braconidae & Aphidius colemani Viereck \\
\hline & & & Habrobracon hebetor (Say) \\
\hline & & Eulophidae & Diglyphus isaea (Walker) \\
\hline & & Trichogrammatidae & Trichogramma evanescens Westwood \\
\hline
\end{tabular}

(http://www.ebi.ac.uk/clustalw). AMPLICON software (Jarman, 2004) was used to design B. tabaci primers. The remaining primers were designed as described in Agustí et al. (2003).

DNA was extracted from individual insects using the DNeasy Tissue Kit (QIAGEN; protocol for animal tissues). Total DNA was eluted in $100 \mu \mathrm{l}$ of AE buffer provided by the manufacturer and stored at $-20^{\circ} \mathrm{C}$. Negative controls were added to each DNA extraction set. Samples were amplified in a 2720 thermal cycler (Applied Biosystems, Foster City, CA, USA). Reaction volumes $(25 \mu \mathrm{l})$ contained $4 \mu \mathrm{l}$ of resuspended DNA. All pairs of primers were amplified by using $0.65 \mathrm{U}$ of Taq DNA polymerase (Invitrogen), $0.25 \mathrm{mM}$ of dNTPs (Promega), $0.4 \mu \mathrm{M}$ of each primer and $1.5 \mathrm{mM}(\mathrm{Em} 2 \mathrm{~F} / \mathrm{Em} 1 \mathrm{R})$, $3 \mathrm{mM}(\mathrm{Bt} 2 \mathrm{~F} / \mathrm{Bt} 3 \mathrm{R}$ and Tv1F/Tv1R) or $6 \mathrm{mM}$ (Ep1F/Ep1R) of $\mathrm{MgCl}_{2}$ in $10 \times$ manufacturer's buffer. Samples were amplified for 35 cycles (except Ep1F/Ep1R, 40 cycles) at $94^{\circ} \mathrm{C}$ for $30 \mathrm{~s}$; $63^{\circ} \mathrm{C}(\mathrm{Tv} 1 \mathrm{~F} / \mathrm{Tv} 1 \mathrm{R}), 62^{\circ} \mathrm{C}(\mathrm{Em} 2 \mathrm{~F} / \mathrm{Em} 1 \mathrm{R})$ or $58^{\circ} \mathrm{C}(\mathrm{Bt} 2 \mathrm{~F} / \mathrm{Bt} 3 \mathrm{R}$ and $\mathrm{Ep} 1 \mathrm{~F} / \mathrm{Ep} 1 \mathrm{R})$ for $30 \mathrm{~s}$; and $72^{\circ} \mathrm{C}$ for $40 \mathrm{~s}$. A first cycle of denaturation at $94^{\circ} \mathrm{C}$ for $3 \mathrm{~min}$ and a final extension at $72^{\circ} \mathrm{C}$ for $5 \mathrm{~min}$ was carried out. Target DNA and water were always included as positive and negative controls, respectively. PCR products were separated by electrophoresis in $1.5 \%$ agarose gels stained with ethidium bromide and visualized under UV light.

\section{Species specificity}

At least ten individuals of each target prey were tested with their respective specific primers to test for intraspecific differences. Ten individuals of the $\mathrm{B}$ and $\mathrm{Q}$ biotypes of B. tabaci, which are the most common in the studied area (Moya et al., 2001) were also analyzed. Specificity of the four pairs of primers was analysed by testing ten individuals of each prey, parasitoid and predator species potentially present in horticultural crops in the study area (table 1). Ephestia kuehniella was also tested as it was the prey of the predators during mass rearing.

\section{Field sampling and analysis of field-collected predators}

Eight tomato greenhouses located near Barcelona (NE Spain), where IPM programs based on conservation of these natural enemies were applied (Castañé et al., 2004), were sampled in summer (May-October) for mirid predators, whiteflies and whitefly parasitoids. In order to determine their abundance, the number of adult whiteflies, as well as nymphs and adults of each predator species, were surveyed on ten leaflets per plant and on 30 plants per greenhouse. For whitefly pupae and parasitoid abundance, 30 tomato leaflets were collected per greenhouse from those leaves where adult whiteflies were starting to emerge from the pupae. The pupae were classified under a binocular microscope as alive, consumed or parasitized. Consumed whitefly pupae were easily distinguished from incomplete predation or other causes of mortality, because complete consumption by a fluid-feeding mirid bug leaves an empty cuticle without an insect emergence hole (Castañé et al., 2004).

Immediately after $M$. pygmaeus and $N$. tenuis were collected, they were placed at $4^{\circ} \mathrm{C}$ and then frozen at $-20^{\circ} \mathrm{C}$ when arriving to the lab. In order to avoid false negatives (Sint et al., 2011), each predator was analyzed up to three times if previous times a positive result was not obtained. One predator was considered negative if prey DNA was not detected in the three analyses. Percentages of molecular detection of each prey species were calculated in each greenhouse, as well as 
Table 2. Whitefly and parasitoid species-specific primer sequences $\left(5^{\prime}-3^{\prime}\right)$, amplified fragment sizes and gene targeted.

\begin{tabular}{lllcr}
\hline Target species & Primer & \multicolumn{1}{c}{ Sequence } & Length (bp) & Region \\
\hline B. tabaci & Bt2 F & TTGGTGTCTCAATTTTATATC & 158 & COI \\
& Bt3R & ATACTCAAAATCCTTCCCGC & & \\
T. vaporariorum & Tv1 F & TCTCACAGGGGTGATTTTG & \multirow{2}{*}{ COI } \\
& Tv1R & CTGGGAAAGAAGAAGGTTAAAA & 187 & \\
E. mundus & Em2 F & CGTATGCGGATAACAACGC & 345 & ITS-1 \\
& Em1 R & GAACTCGCAAGAGCTCGAAC & & \\
E. pergandiella & Ep1 F & ACGCAAGTCGTACCGATGAG & 314 & ITS-1 \\
& Ep1R & AAACGTAACTTTGACGACGC & & \\
\hline
\end{tabular}

percentages of multiple prey detection in the same individual predator.

Whitefly pupae and adult abundances were compared with whitefly molecular detection percentages in each greenhouse for both predator species. Abundances of nonparasitized and parasitized pupae were combined because whitefly DNA could also be detected in the parasitized pupae, depending on the parasitoid developmental stage (data not shown). Abundance of parasitized pupae was also compared with parasitoid molecular detection. The number of predators testing positive for whitefly DNA was also compared with the mean numbers of predated whitefly pupae in each greenhouse. The number of positive predators of both species was added, as it was not possible to determine which species had fed on the whitefly pupae when both predator species were present.

Multiple regression analyses were done to evaluate the relationships between molecular detection and the number of available whitefly pupae and adults, parasitized and predated prey (SAS Institute Inc., 2001). The available and predated whitefly data were $\log _{n}$-transformed.

In order to determine whether prey detection depended on predator species, molecular detection percentages of both whiteflies within each predator species were studied. A twotailed Fisher exact test was performed (SAS Institute Inc., 2001).

\section{Results}

\section{Species specificity}

Specific primers that were designed for B. tabaci, T. vaporariorum, E. mundus and E. pergandiella (table 2 ) showed successful amplifications of the target prey in all cases (fig. 1). In the case of $B$. tabaci, B and Q biotypes were both successfully amplified. When the four pairs of primers were tested for cross-amplification against other potential prey (26 species belonging to 14 families; see table 1), only the target prey were detected, thus showing a high degree of primer specificity.

\section{Predation in greenhouses}

\section{Predator-prey abundance and prey molecular detection}

Predator and prey abundances found in the eight sampled greenhouses are shown in table 3. Macrolophus pygmaeus was found in all greenhouses where it was sampled (greenhouse A was not sampled for abundances, although predators were collected for molecular analysis), while N. tenuis was found only in four. Predator nymphs were more abundant than adults in all greenhouses, except in greenhouse $\mathrm{G}$ for $N$. tenuis.

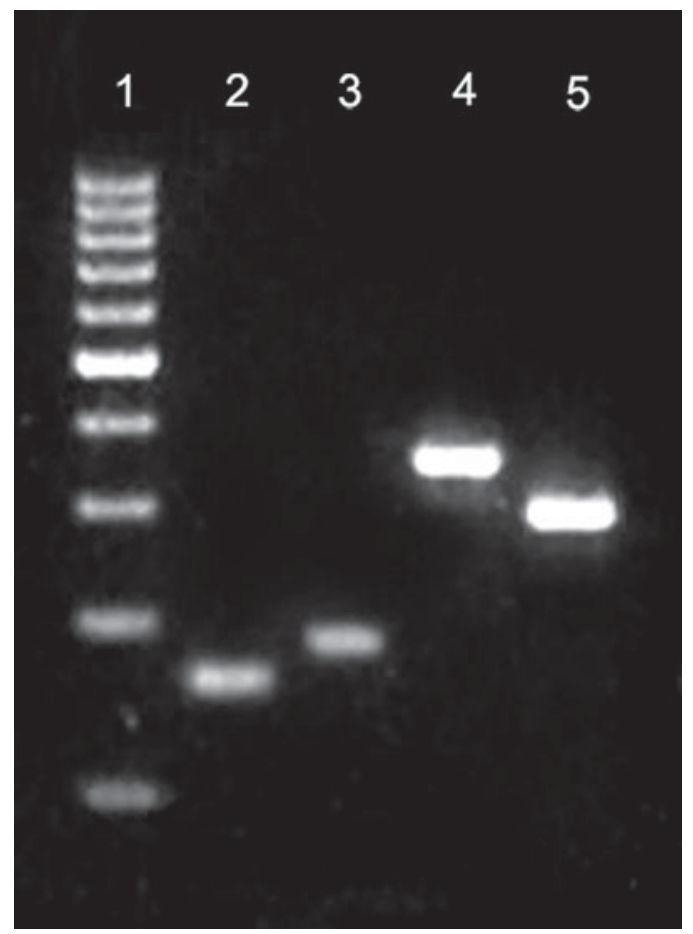

Fig. 1. Amplification products obtained with the specific primers for the four target prey. Lane 2, Bemisia tabaci (158bp); 3, Trialeurodes vaporariorum (187bp); 4, Eretmocerus mundus (345bp); 5, Encarsia pergandiella (314bp). Lane 1, $100 \mathrm{bp}$ DNA ladder.

Trialeurodes vaporariorum adult abundance was higher than $B$. tabaci in four of the sampled greenhouses, while the same was found for $T$. vaporariorum pupae in six of them. The abundance of pupae parasitized by E. mundus and E. pergandiella was low, except in greenhouse $\mathrm{A}$, where E. pergandiella reached a very high level $(34.6 \pm 8.81$ pupae per leaflet).

Percentages of prey detection by PCR in the eight sampled greenhouses are shown in table 4 . Predators were collected from 30 plants per greenhouse, but only those greenhouses with more than 14 collected predators were analysed by PCR. Therefore, although low densities of N. tenuis and M. pygmaeus were observed in greenhouses $\mathrm{E}$ and $\mathrm{F}$, respectively, analyses were not conducted. All prey species were detected by PCR in both predator species. Prey was detected in 39\% $(n=142)$ of M. pygmaeus and in $46 \%(n=61)$ of $N$. tenuis. Bemisia tabaci and $T$. vaporariorum molecular detection was achieved in all 
Table 3. Predator and prey abundances $($ mean \pm SE) in eight tomato greenhouses.

\begin{tabular}{|c|c|c|c|c|c|c|c|c|c|c|}
\hline \multirow[t]{3}{*}{$\overline{\text { Greenhouse }}$} & \multicolumn{4}{|c|}{ Predator abundance } & \multicolumn{6}{|c|}{ Prey abundance } \\
\hline & \multicolumn{2}{|c|}{ M. pygmaeus/plant } & \multicolumn{2}{|c|}{ N. tenuis/plant } & \multicolumn{2}{|c|}{ Adults/plant } & \multicolumn{4}{|c|}{ Pupae/leaflet } \\
\hline & Adults & Nymphs & Adults & Nymphs & $\mathrm{Bt}$ & $\mathrm{Tv}$ & $\mathrm{Bt}$ & Em & $\mathrm{Tv}$ & Ep \\
\hline B & $0.2 \pm 0.12$ & $1.2 \pm 0.26$ & 0 & 0 & 0 & $3.8 \pm 0.93$ & $0.3 \pm 0.17$ & 0 & $4.3 \pm 1.00$ & $0.7 \pm 0.25$ \\
\hline $\mathrm{C}$ & $0.8 \pm 0.21$ & $2.8 \pm 0.39$ & 0 & 0 & 0 & $5.9 \pm 1.06$ & $0.6 \pm 0.39$ & 0 & $1.7 \pm 0.33$ & $0.4 \pm 0.15$ \\
\hline D & $0.1 \pm 0.06$ & $0.5 \pm 0.15$ & 0 & 0 & $1.0 \pm 0.23$ & $3.3 \pm 0.66$ & $0.6 \pm 0.24$ & 0 & $3.4 \pm 0.80$ & $0.1 \pm 0.13$ \\
\hline G & $0.1 \pm 0.05$ & $0.5 \pm 0.18$ & $1.4 \pm 0.23$ & $1.1 \pm 0.25$ & $1.3 \pm 0.27$ & $0.3 \pm 0.15$ & 0 & 0 & $0.1 \pm 0.08$ & 0 \\
\hline $\mathbf{H}$ & $0.1 \pm 0.05$ & $0.4 \pm 0.13$ & $0.2 \pm 0.11$ & $0.4 \pm 0.13$ & $3.9 \pm 0.82$ & $1.6 \pm 0.30$ & $1.8 \pm 0.92$ & $0.1 \pm 0.08$ & $2.9 \pm 1.04$ & $1.1 \pm 0.54$ \\
\hline
\end{tabular}

Bt, B. tabaci; Tv, T. vaporariorum; Em, B. tabaci parasitized by E. mundus; Ep, T. vaporariorum parasitized by E. pergandiella.

Table 4. Predated prey observed under microscope (mean \pm SE) and percentages of positive M. pygmaeus and N. tenuis by PCR in eight tomato greenhouses.

\begin{tabular}{|c|c|c|c|c|c|c|c|c|c|c|c|c|}
\hline \multirow[t]{3}{*}{ Greenhouse } & \multirow{2}{*}{\multicolumn{2}{|c|}{$\begin{array}{l}\text { Consumed whitefly } \\
\text { pupae per leaflet }\end{array}$}} & \multicolumn{10}{|c|}{ Molecular detection } \\
\hline & & & \multicolumn{5}{|c|}{ M. pygmaeus (\%) } & \multicolumn{5}{|c|}{ N. tenuis (\%) } \\
\hline & $\mathrm{Bt}$ & $\mathrm{Tv}$ & $\mathrm{Bt}$ & Em & $\mathrm{Tv}$ & Ep & $n$ & $\mathrm{Bt}$ & Em & $\mathrm{Tv}$ & Ep & $n$ \\
\hline B & 0 & $2.9 \pm 0.92$ & 18.8 & - & 37.5 & 6.3 & 16 & - & - & - & - & - \\
\hline C & 0 & $2.4 \pm 0.52$ & 0.0 & - & 41.7 & 0.0 & 24 & - & - & - & - & - \\
\hline D & 0 & $1.0 \pm 0.31$ & 22.2 & 5.6 & 44.4 & 0.0 & 18 & - & - & - & - & - \\
\hline G & 0 & $4.9 \pm 1.01$ & 35.7 & - & 21.4 & 14.3 & 14 & 4.2 & - & 0.0 & 0.0 & 24 \\
\hline $\mathbf{H}$ & $0.6 \pm 0.32$ & $2.0 \pm 0.51$ & 20.0 & 5.0 & 15.0 & 0.0 & 20 & 37.5 & 0.0 & 50.0 & 18.8 & 16 \\
\hline
\end{tabular}

Bt, B. tabaci; Tv, T. vaporariorum; Em, B. tabaci parasitized by E. mundus; Ep, T. vaporariorum parasitized by E. pergandiella; $n$, number of predators analyzed.

greenhouses where they were present, except in two cases: $B$. tabaci in greenhouse $C$, where only $B$. tabaci pupae were found; and T. vaporariorum in greenhouse E, where only adults were found and with the lowest abundance (table 3). However, predated B. tabaci pupae were only observed microscopically in two of the seven greenhouses. Therefore, molecular techniques were more likely than microscopy to detect the occurrence of rare predation events, as is shown in the detection of predation by M. pygmaeus on B. tabaci in four greenhouses where predation was not observed upon microscopic examination. Also, in those greenhouses where both M. pygmaeus and N. tenuis were present and analysed by PCR ( $G$ and $H)$, molecular detection identified which whitefly species were being consumed by each predator species. In addition, E. mundus predation was detected by molecular analysis in all greenhouses where it was visually observed ( $\mathrm{F}$ and $\mathrm{H}$; see table 4 ), while E. pergandiella predation was detected only in three of the five greenhouses where it was documented in visual counts. In two greenhouses, molecular detection of one parasitoid was possible even when they were not observed (E. pergandiella in greenhouse $\mathrm{G}$ and $E$. mundus in greenhouse D), again reaffirming the utility of molecular techniques in the detection of rare predation events.

\section{Relationship between prey abundance and molecular detection}

Detection of whitefly DNA in predators was positively correlated with whitefly adult abundance (both whitefly species together) for both predator species $\left(\mathrm{r}^{2}=0.55 ; P=0.009\right.$ for M. pygmaeus and $\mathrm{r}^{2}=0.67 ; P=0.045$ for $N$. tenuis; fig. $2 \mathrm{a}, \mathrm{b}$ ). Similarly, when whitefly pupae abundances (both whitefly species together) were related to molecular detection of whitefly DNA within predators, a significant positive relationship was found for $N$. tenuis $\left(\mathrm{r}^{2}=0.88 ; P=0.005\right.$; fig. $\left.2 \mathrm{~d}\right)$ but not significant for $M$. pygmaeus $\left(\mathrm{r}^{2}=0.28 ; P=0.079\right.$; fig. 2c). There was no significant relationship between parasitized whitefly pupae (both parasitoid species together) and detection of parasitoid DNA in $M$. pygmaeus $\left(r^{2}=0.21 ; P=0.304\right)$. This relationship was not calculated in $N$. tenuis because parasitoids were only found in two greenhouses together with this predator (see table 3 ), which was not enough to determine a relationship.

No significant relationship was found between the number of predated whitefly pupae observed under the microscope (table 4 ) and the whitefly DNA detected in the two predator species $\left(r^{2}=0.02 ; P=0.679\right)$.

\section{Multiple prey molecular detection}

Up to three different prey species were detected in both predator species (table 5). From the 56 M. pygmaeus in which prey were detected, one prey species was detected in $77 \%$ of them, two prey species were detected in $21 \%$ and three prey species were detected in only $2 \%$. From the $28 \mathrm{~N}$. tenuis in which the prey was detected, $46 \%$ were positive for one prey 
M. pygmaeus

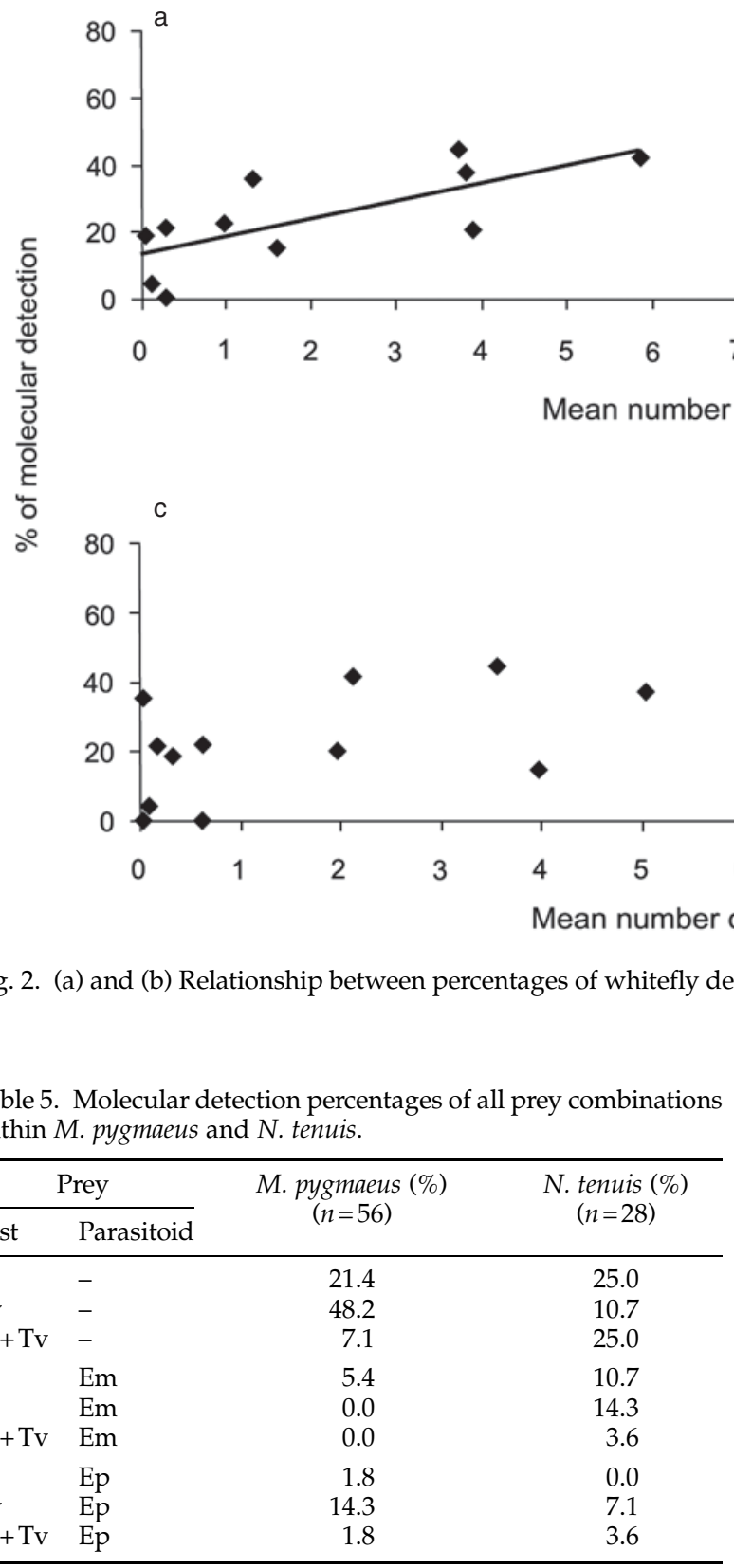

Bt, B. tabaci; Tv, T. vaporariorum; Em, E. mundus; Ep, E. pergandiella.

species, $46 \%$ for two and $7 \%$ for three, showing possibly greater polyphagy by this predator species.

Forty-five per cent of the predators positive for $E$. mundus were also positive for $B$. tabaci, while $92 \%$ of the predators positive for E. pergandiella were also positive for T. vaporariorum.

\section{Prey molecular detection depending on predator species}

Considering the particular case of greenhouse $\mathrm{H}$, where both whitefly species and both predators where present $(n=20$ M. pygmaeus and $n=16 N$. tenuis), whitefly detection was higher within $N$. tenuis than within $M$. pygmaeus, and
N. tenuis

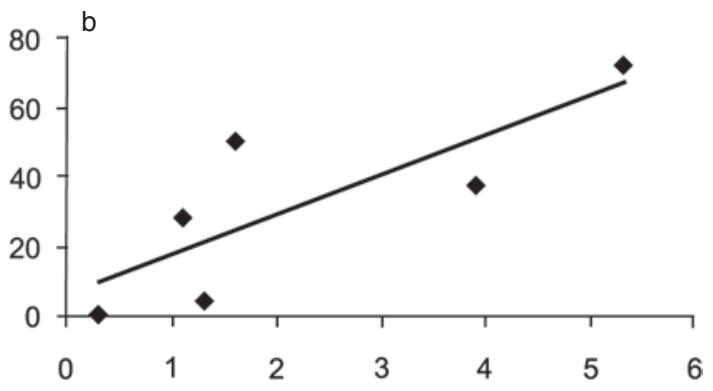

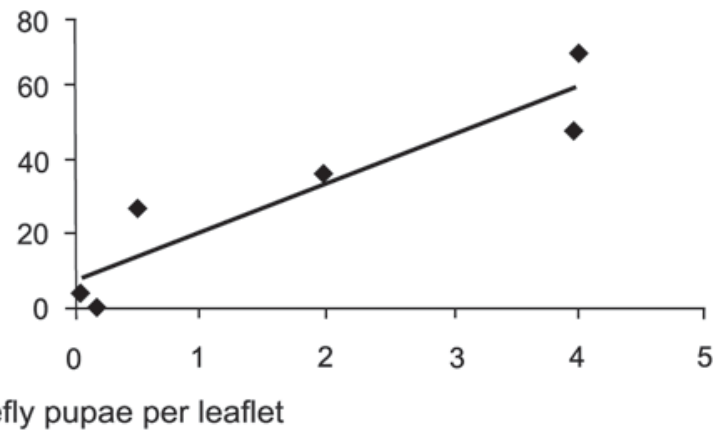

(d) whitefly pupae presence.
(d)

significantly higher (two-tailed Fisher's exact test, $P=0.034$ ) in the case of $T$. vaporariorum (fig. 3 ).

\section{Discussion}

In the present study, it was demonstrated that both predators were feeding on both whitefly species, as well as on both parasitoid species under greenhouse conditions. Prey molecular detection was possible in greenhouses where prey abundance was very low or even not observed under a microscope. This suggests that predators are also feeding on small life stages of parasitoids (eggs and early larvae), which are very difficult or impossible to detect inside the whitefly by direct observation or dissection. This molecular technique provides improved detection of prey consumption in greenhouse crops, as well as the possibility to identify which prey species were fed by each predator species present in the same greenhouse, which was impossible in previous studies using traditional methods (Castañé et al., 2004; Arnó et al., 2005).

Whitefly molecular detection within both predators was significantly related to the adult whitefly abundance found in the greenhouses, as well as to whitefly pupae abundance in the case of N. tenuis. Montserrat et al. (2000b) observed a higher efficiency of $M$. pygmaeus preying on second-instar larvae of Frankliniella occidentalis (small and mobile) than on fourthinstar nymphs of $T$. vaporariorum (bigger and sessile). This suggests that $M$. pygmaeus could be attracted to mobile prey, which could explain the significant relationship between whitefly molecular detection and the abundance of adult 


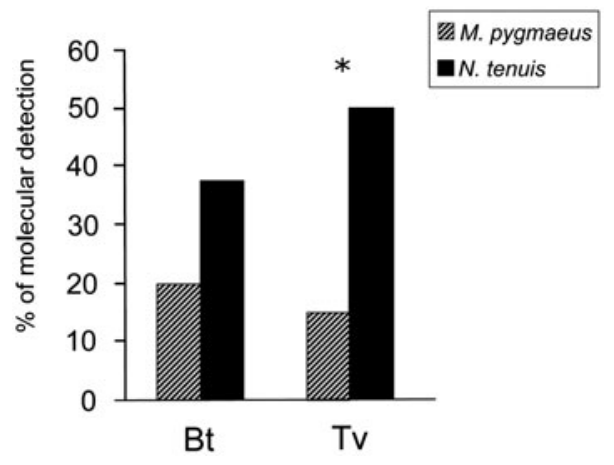

Fig. 3. Prey molecular detection percentages within M. pygmaeus and $N$. tenuis from greenhouse $H .{ }^{*}$, significant difference between M. pygmaeus and N. tenuis. $\mathrm{Bt}, B$. tabaci; $\mathrm{Tv}, T$. vaporariorum.

whitefly within the same predator. Another explanation would be related to the distribution on the plant. Adult whiteflies, mainly $T$. vaporariorum, tend to congregate in the upper leaves of the tomato plant (Arnó et al., 2006), an area which also supports larger predator populations (Arnó et al., 2010).

As expected, no relationship was found between whitefly DNA detected in predators and the observed predation on whiteflies. The number of predated whitefly pupal husks observed on the leaves is the result of predation over an extended period of time. It is not possible to know when these pupae were consumed or which predator species had fed on them. Also, no relationship was observed between parasitoid molecular detection and parasitoid abundance, as estimated by visual inspection of leaves. This suggests an underestimation of parasitism under the microscope because of the difficulty of observing parasitoid egg and larval stages. Even if these predators have been reported previously to prey on E. mundus pupae, immature stages and adults in laboratory studies (Malo, 2009), molecular methods are probably optimal for future work looking at the predators' impact on parasitoids, as these techniques provide more sensitive speciesspecific detection.

The molecular analysis of field collected predators allowed the identification of up to three different prey species in some of the analysed predators. Intraguild predation may be advantageous when pest species are scarce (van Baalen et al., 2001) or disadvantageous when predators reduce the effectiveness of parasitoids by feeding on them (Rosenheim et al., 1995). Therefore, analysis of predation rates on parasitized prey can be important when determining the effectiveness of polyphagous predators simultaneously with parasitoids (Hoelmer et al., 1994). Although the number of specimens analyzed in the present study was fairly low, we show that both predators fed mainly on whiteflies $(76.7 \%$ for M. pygmaeus and $60.7 \%$ for N. tenuis) but also on parasitoids ( $23.3 \%$ and $39.3 \%$, respectively). As mentioned before, previous studies have already shown intraguild predation on parasitoids under field conditions using molecular tools. Chacón et al. (2008) showed predation on the parasitoid Aphidius colemani by Harmonia axyridis and Chrysoperla carnea. Similarly, Traugott et al. (2011) showed predation on several species of aphid parasitoids by generalist predators. Other studies indicate that joint presence of these predators and these parasitoids could be complementary (Castañé et al., 2004; Gabarra et al., 2006). The present study shows that predation on E. mundus and E. pergandiella by M. pygmaeus and $N$. tenuis under greenhouse conditions is common and could have a negative effect on biological control. However, further experiments or larger scale collections are necessary to confirm the existence and impact of such interactions on the success of biological control of whiteflies.

Although E. pergandiella has been described as a B. tabaci parasitoid (Liu \& Stansly, 1996), the combination of B. tabaci and E. pergandiella DNA was not detected in predators. This suggests preference by this parasitoid for T. vaporariorum when both whitefly species are available. Similar results were found when natural parasitism by both parasitoids on whiteflies in tomato and cucumber crops were studied (Arnó et al., 2005).

Molecular prey detection was higher in N. tenuis than in M. pygmaeus. Although it can be the result of a lower digestion rate in $N$. tenuis, a higher voracity of this predator species could also explain this difference. This would agree with previously published studies, like Arnó et al. (2009), who compared the predatory capacity of both predators on T. absoluta eggs and observed that M. pygmaeus nymphs preyed significantly less than N. tenuis nymphs. Barnadas et al. (1998) also observed that $M$. caliginosus consumed fewer B. tabaci and $T$. vaporariorum pupae than the mirid D. tamaninii. Finally, Montserrat et al. (2000a) found lower prey searching activity in M. caliginosus than in D. tamaninii.

This study has demonstrated the effectiveness of molecular markers to study predation in agroecosystems, including greenhouse tomato crops. Here, trophic interactions were detected between the polyphagous predators $M$. pygmaeus and $N$. tenuis in the presence of the whiteflies $B$. tabaci and $T$. vaporariorum and two parasitoids under field conditions. This predation on the parasitoids indicates the existence of intraguild predation, which could interfere with the biological control of those whitefly pests. The extent of this impact on a biological control program needs to be investigated further. Nonetheless, the molecular markers described here provide valuable information that would be difficult or impossible to obtain by other methods.

\section{Acknowledgements}

We thank Victor Muñoz, Pilar Hernández, Francisca Oliver, Thaïs Aznar, Faten Hamdi and Ramon Berruezo for their technical support and Lluis Torres and Pablo Manzano for the statistical support. We also thank the anonymous reviewers and the subject editor for improving the manuscript. This work has been funded by the Spanish Ministry of Science and Innovation (MICINN) (Projects AGL2008-00546 and AGL2010-18811). R. Moreno-Ripoll was supported by a FPI grant and N. Agustí by the Program Ramón y Cajal, both funded by the MICINN.

\section{References}

Agustí, N. \& Gabarra, R. (2009a) Puesta a punto de una cría masiva del depredador polífago Dicyphus tamaninii Wagner (Heteroptera: Miridae). Boletin Sanidad Vegetal: Plagas 35, 205-218.

Agustí, N. \& Gabarra, R. (2009b) Effect of adult age and insect density of Dicyphus tamaninii Wagner (Heteroptera: Miridae) on progeny. Journal of Pest Science 82, 241-246.

Agustí, N., Shayler, S., Harwood, J.D., Vaughan, I.P., Sunderland, K.D. \& Symondson, W.O.C. (2003) 
Collembola as alternative prey sustaining spiders in arable ecosystems: prey detection within predators using molecular markers. Molecular Ecology 12, 3467-3475.

Agustí, N., Bourguet, D., Spataro, T., Delos, M., Eychenne, N., Folcher, L. \& Arditi, R. (2005) Detection, identification and geographical distribution of European corn borer larval parasitoids using molecular markers. Molecular Ecology 14, 3267-3274.

Albajes, R. \& Alomar, O. (1999) Current and potential use of polyphagous predators. pp. 265-275 in Albajes, R., Gullino, M.L., van Lenteren, J.C. \& Elad, Y. (Eds) Integrated Pest and Disease Management in Greenhouse Crops. Dordrecht, Netherlands, Kluwer Academic Publishers.

Albajes, R., Sarasúa, M.J., Avilla, J., Arnó, J. \& Gabarra, R. (2003) Integrated pest management in the mediterranean region: the case of Catalonia, Spain. pp. 341-355 in Maredia, K.M., Dakouo, D. \& Mota-Sanchez, D. (Eds) Integrated Pest Management in the Global Arena. Wallingford, UK, CABI Publishing.

Arnó, J., Matas, M., Martí, M., Ariño, J., Roig, J. \& Gabarra, R. (2005) Coexistence between Trialeurodes vaporariorum and Bemisia tabaci and impact of natural enemies in tomato crops under Mediterranean conditions. IOBC/WPRS Bulletin 28, 1-4.

Arnó, J., Albajes, R. \& Gabarra, R. (2006) Within-plant distribution and sampling of single and mixed infestations of Bemisia tabaci and Trialeurodes vaporariorum (Homoptera: Aleyrodidae) in winter tomato crops. Journal of Economic Entomology 99, 331-340.

Arnó, J., Sorribas, R., Prat, M., Matas, M., Pozo, C., Rodríguez, D., Garreta, A., Gómez, A. \& Gabarra, R. (2009) Tuta absoluta, a new pest in IPM tomatoes in the northeast of Spain. IOBC/WPRS Bulletin 49, 203-208.

Arnó, J., Castañé, C., Riudavets, J. \& Gabarra, R. (2010) Risk of damage to tomato crops by the generalist zoophytophagous predator Nesidiocoris tenuis (Reuter) (Hemiptera: Miridae). Bulletin of Entomological Research 100, 105-115.

Avilla, J., Albajes, R., Alomar, O., Castañé, C. \& Gabarra, R. (2004) Biological control of whiteflies in protected vegetable crop. pp. 171-184 in Parrella, M.P. \& Heinz, K.M. (Eds) Biological Control of Arthropods Pests in Protected Culture. Batavia, IL, USA, Ball Publishing.

Barnadas, I., Gabarra, R. \& Albajes, R. (1998) Predatory capacity of two mirid bugs preying on Bemisia tabaci. Entomologia Experimentalis et Applicata 86, 215-219.

Calvo, F.J., Bolckmans, K. \& Belda, J.E. (2009) Development of a biological control-based Integrated Pest Management metod for Bemisia tabaco for protected sweet pepper crops. Entomologia Experimentalis et Applicata 133, 9-18.

Castañé, C., Alomar, O., Goula, M. \& Gabarra, R. (2004) Colonization of tomato greenhouses by the predatory mirid bugs Macrolophus caliginosus and Dicyphus tamaninii. Biological Control 30, 591-597.

Chacón, J.M., Landis, D.A. \& Heimpel, G.E. (2008) Potential for biotic interference of a classical biological control agent of the soybean aphid. Biological Control 46, 216-225.

Gabarra, R. \& Besri, M. (1999) Tomatoes. pp. 420-434 in Albajes, R., Gullino, M.L., van Lenteren, J.C. \& Elad, Y. (Eds) Integrated Pest and Disease Management in Greenhouse Crops. Dordrecht, Netherlands, Kluwer Academic Publishers.

Gabarra, R., Arnó, J., Alomar, O. \& Albajes, R. (1999) Naturally occurring populations of Encarsia pergandiella (Hymenoptera: Aphelinidae) in tomato greenhouses. IOBC/WPRS Bulletin 22, 85-88.
Gabarra, R., Zapata, R., Castañé, C., Riudavets, J. \& Arnó, J. (2006) Releases of Eretmocerus mundus and Macrolophus caliginosus for controling Bemisia tabaci on spring and autumn greenhouse tomato crops. IOBC/WPRS Bulletin 29, 71-76.

Gariepy, T.D., Kuhlmann, U., Gillott, C. \& Erlandson, M. (2007) Parasitoids, predators and PCR: the use of diagnostic molecular markers in biological control of Arthropods. Journal of Applied Entomology 131, 225-240.

Harper, G.L., King, R.A., Dodd, C.S., Harwood, J.D., Glen, D.M., Bruford, M.W. \& Symondson, W.O.C. (2005) Rapid screening of invertebrate predators for multiple prey DNA targets. Molecular Ecology 14, 819-827.

Harwood, J.D., Desneux, N., Yoo, H.Y.S., Rowley, D.L., Greenstone, M.H., Obrycki, J.J. \& O'Neil, R.J. (2007) Tracking the role of alternative prey in soybean aphid predation by Orius insidiosus: a molecular approach. Molecular Ecology 16, 4390-4400.

Hoelmer, K.A., Osborne, L.S. \& Yokomi, R.K. (1994) Interactions of the whitefly predator Delphastus pusillus (Coleoptera: Coccinellidae) with parasitized sweetpotato whitefly (Homoptera: Aleyrodidae). Environmental Entomology 23, 136-139.

Jarman, S.N. (2004) Amplicon: software for designing PCR primers on aligned DNA sequences. Bioinformatics 20, 1644-1645.

Juen, A. \& Traugott, M. (2007) Revealing species-specific trophic links in soil food webs: molecular identification of scarab predators. Molecular Ecology 16, 1545-1557.

King, R.A., Read, D.S., Traugott, M. \& Symondson, W.O.C. (2008) Molecular analysis of predation: a review of best practice for DNA-based approaches. Molecular Ecology 17, 947-963.

Kuusk, A.-K., \& Agustí, N. (2008) Group-specific primers for DNA-based detection of springtails (Hexapoda: Collembola) within predator gut contents. Molecular Ecology Resources 8, 678-681.

Kuusk, A.-K., Cassel-Lundhagen, A., Kvarnheden, A. \& Ekbom, B. (2008) Tracking aphid predation by lycosid spiders in spring-sown cereals using PCR-based gutcontent analysis. Basic and Applied Ecology 9, 718-725.

Liu, T.X. \& Stansly, P.A. (1996) Oviposition, development, and survivorship of Encarsia pergandiella (Hymenoptera: Aphelinidae) in four instars of Bemisia argentifolii (Homoptera: Aleyrodidae). Annals of the Entomological Society of America 89, 96-102.

Malo, S. (2009) Biological control of Bemisia tabaci (Homoptera: Aleyrodidae): Eretmocerus mundus (Hymenoptera: Aphelinidae), Macrolophus pygmaeus (Heteroptera: Miridae) and its interaction [Control biològic de Bemisia tabaci (Homoptera: Aleyrodidae): Eretmocerus mundus (Hymenoptera: Aphelinidae), Macrolophus pygmaeus (Heteroptera: Miridae) i la seva interacció]. PhD thesis, University of Lleida, Spain (in Catalan).

Martinez-Cascales, J.I., Cenis, J.L., Cassis, G. \& Sanchez, J.A. (2006) Species identity of Macrolophus melanotoma (Costa 1853) and Macrolophus pygmaeus (Rambur 1839) (Insecta: Heteroptera: Miridae) based on morphological and molecular data and bionomic implications. Insect Systematics \& Evolution 37, 385-404.

Montserrat, M., Albajes, R. \& Castañé, C. (2000a) Comparative behaviour of three predators used in biological control in greenhouse crops. IOBC/WPRS Bulletin 23, 267-272.

Montserrat, M., Albajes, R. \& Castañé, C. (2000b) Functional response of four heteropteran predators preying on 
greenhouse whitefly (Homoptera: Aleyrodidae) and western flower thrips (Thysanoptera: Thripidae). Environmental Entomology 29, 1075-1082.

Moya, A., Guirao, P., Cifuentes, D., Beitia, F. \& Cenis, J.L. (2001) Genetic diversity of Iberian populations of Bemisia tabaci (Hemiptera: Aleyrodidae) based on random amplified polymorphic DNA-polymerase chain reaction. Molecular Ecology 10, 891-897.

Rosenheim, J.A., Kaya, H.K., Ehler, L.E., Marois, J.J. \& Jaffee, B.A. (1995) Intraguild predation among biologicalcontrol agents: theory and evidence. Biological Control 5, 303-335.

SAS Institute Inc. (2001) The SAS System for Windows 8.02. SAS Institute, Cary, NC, USA.

Sint, D., Raso, L., Kaufmann, R. \& Traugott, M. (2011) Optimizing methods for PCR-based analysis of predation. Molecular Ecology Resources 11, 795-801.
Symondson, W.O.C. (2002) Molecular identification of prey in predator diets. Molecular Ecology 11, 627-641.

Traugott, M. \& Symondson, W.O.C. (2008) Molecular analysis of predation on parasitized hosts. Bulletin of Entomological Research 98, 223-231.

Traugott, M., Bell, J.R., Raso, L., Sint, D. \& Symondson, W.O.C. (2011) Generalist predators disrupt parasitoid aphid control by direct and coincidental intraguild predation. Bulletin of Entomological Research, doi: 10.1017/S0007485311000551.

van Baalen, M., Krivan, V., van Rijn, P.C.J. \& Sabelis, M.W. (2001) Alternative food, switching predators, and the persistence of predator-prey systems. American Naturalist 157, 512-524.

Zhang, G.F., Lü, Z.C. \& Wan, F.H. (2007) Detection of Bemisia tabaci remains in predator guts using a sequencecharacterized amplified region marker. Entomologia Experimentalis et Applicata 123, 81-90. 